\title{
PENGARUH E-WOM DAN PERSEPSI NILAI TERHADAP KEPUTUSAN PEMBELIAN SHOPEEFOOD DENGAN MEDIASI KEPERCAYAAN
}

\author{
Felix Yohansyah ${ }^{1}$, Rodhiah $^{2}$ \\ ${ }^{1}$ Program Studi Manajemen, Fakultas Ekonomi dan Bisnis, Universitas Tarumanagara \\ Email: felix.115170117@stu.untar.ac.id \\ ${ }^{2}$ Program Studi Manajemen, Fakultas Ekonomi dan Bisnis, Universitas Tarumanagara* \\ Email: rodhiah@fe.untar.ac.id \\ *Penulis Korespondensi
}

Masuk : 02-08-2021, revisi: 15-08-2021, diterima untuk diterbitkan : 30-08-2021

\begin{abstract}
ABSTRAK
Tujuan dari penelitian ini adalah menguji pengaruh e-wom dan persepsi nilai terhadap keputusan pembelian serta menguji kepercayaan sebagai mediasi antara e-wom, persepsi nilai, dan keputusan pembelian. Populasi dari penelitian ini adalah 100 orang pengguna ShopeeFood di Jakarta. Metode pemilihan sampel dilakukan dengan non probability sampling menggunakan teknik convenience sampling. Teknik pengumpulan data digunakan dengan menyebarkan kuisioner secara online melalui google-form. Teknik analisis data menggunakan structural equation model atau SEM. Pengolahan data menggunakan software smartPLS 3.0. Hasil dari penelitian ini adalah e-WOM memiliki pengaruh yang positif terhadap keputusan pembelian, persepsi nilai memiliki pengaruh yang positif terhadap keputusan pembelian, kepercayaan mempengaruhi keputusan pembelian secara positif. e-WOM dan persepsi nilai dapat mempengaruhi keputusan pembelian secara positif melalui mediasi kepercayaan. Jadi dapat di simpulkan ShopeeFood perlu memperhatikan e-WOM dan persepsi nilai dalam meningkatkan keputusan pembelian makanan oleh pelanggan.
\end{abstract}

Kata Kunci: E-WOM, Persepsi Nilai, Kepercayaan, Keputusan Pembelian

\section{ABSTRACT}

The purpose of this study was to examine the effect of e-wom and perceived value on purchase decision and to examine trust as a mediation between e-wom, perceived value, and purchase decision. The population of this research is 100 ShopeeFood users in Jakarta. The sample selection method was carried out by non-probability sampling using a convenience sampling technique. Data collection techniques were used by distributing online questionnaires via google-form. The data analysis technique uses a structural equation model or SEM. Data processing using smartPLS 3.0 software. The results of this study are e-WOM has a positive influence on purchasing decisions, perceived value has a positive influence on purchasing decisions, trust has a positive influence on purchasing decisions. e-WOM and perceived value can positively influence purchasing decisions through trust mediation.

Keywords: E-WOM, Perceived Value, Trust, Purchase Decision

\section{PENDAHULUAN \\ Latar Belakang}

Pada era digital ini manusia sudah sangat bergantung kepada teknologi khususnya internet untuk memenuhi kebutuhan masyarakat yang semakin tinggi dan beragam. Pengguna internet di Indonesia berdasarkan survei yang dilakukan oleh Asosiasi Penyelenggara Jasa Internet Indonesia (APJII) pada tahun 2020 sudah mencapai 196,7 juta jiwa. Dengan adanya pandemi Covid-19 maka semakin mempercepat dan juga memperbanyak orang untuk menggunakan internet dalam kegiatan sehari - harinya. Salah satu bentuk kegiatannya adalah memesan makanan melalui internet dengan aplikasi ShopeeFood. 
Layanan pesan antar online kini banyak digunakan oleh masyarakat terutama yang tinggal di area perkotaan karena memudahkan konsumen seperti menghemat waktu atau tenaga sehingga tidak perlu mengantri langsung dan juga promo - promo menarik yang diberikan oleh perusahaan maupun terdapat konsumen yang ingin mencoba makanan yang menjadi tren, tidak bisa memasak ataupun lapar tengah malam yang pada akhirnya konsumen melakukan keputusan pembelian menggunakan aplikasi ini. Dalam menentukan keputusan pembelian maka pelanggan akan mencoba untuk mencari tahu dulu tentang layanan yang akan mereka gunakan melalui ulasan yang ada salah satunya di internet, hal tersebut dilakukan agar pelanggan dapat merasa lebih aman dan nyaman.

ShopeeFood juga gencar dalam melakukan kegiatan pemasaran seperti melakukan promo gratis ongkir dan memasang iklan yang unik pada platform - platform yang ada di internet seperti media sosial Youtube dan Instagram. Dukungan selebriti juga merupakan salah satu faktor yang dapat mempengaruhi keputusan pembelian oleh konsumen, Zamudio (2016) dalam penelitiannya menyatakan dukungan selebriti adalah pembuktian yang dibuat dan dilakukan oleh tokoh masyarakat untuk suatu merek dengan tujuan meningkatkan daya tarik dari merek tersebut. Sehingga pelanggan akan memberikan kesan terhadap pengalamannya dalam menggunakan layanan tersebut yang dapat berdampak langsung kepada ShopeeFood.

Dilihat dari beberapa penelitian sebelumnya seperti penelitian Prasad et al. (2018) yang meneliti generasi Y di India, hasilnya menunjukkan hubungan yang signifikan antara e-WOM dan keputusan pembelian, dan Pooe (2013) yang dilakukan di Afrika Selatan tentang persepsi nilai terhadap keputusan pembelian juga mendapatkan hasil yang positif. Perbedaan penelitian ini dibandingkan dengan penelitian yang sudah ada, yaitu belum terdapat penelitan yang membahas apa penyebab terjadinya keputusan pembelian melalui aplikasi ShopeeFood yang dimana baru diluncurkan tetapi sudah banyak digunakan oleh pelanggan. Maka dari itu peneliti tertarik untuk meneliti e-WOM dan persepsi nilai terhadap keputusan pembelian ShopeeFood dengan mediasi kepercayaan.

\section{Kajian teori \\ E-WOM}

Menurut Machado dan Rodhiah (2020), e-WOM merupakan pernyataan positif atau negatif yang dibuat oleh calon, pelanggan aktual atau mantan tentang suatu produk atau perusahaan dari penerima kepada pengirim, yang disediakan melalui saluran online. Soares et al. (2012) mendefinisikan e-WOM sebagai komunikasi pribadi tentang merek, produk, atau layanan yang dianggap non-komersial. Berdasarkan definisi di atas, dapat disimpulkan bahwa e-WOM adalah cara atau bentuk penyampaian suatu informasi yang bersifat pribadi tentang suatu produk atau jasa yang dapat mempengaruhi konsumen terhadap merek ataupun produk atau jasanya.

\section{Perceived Value}

Definisi persepsi nilai menurut Keller et al. (2016) menyatakan bahwa proses yang digunakan oleh individu untuk memilih, mengorganisasi, dan menginterpretasi masukan informasi guna menciptakan gambaran dunia yang memiliki arti. Menurut Putra dan Keni (2020), perceived value merupakan penilaian pelanggan atas evaluasi konsumsi berdasarkan seberapa besar manfaat yang akan diterima dibandingkan dengan seberapa besar upaya yang harus dikeluarkan untuk mendapatkannya. Berdasarkan definisi diatas, dapat disimpulkan bahwa persepsi nilai merupakan penilaian oleh pelanggan terhadap suatu produk berdasarkan informasi yang masuk atau diterima. 


\section{Trust}

Menurut Morgan dan Hunt (1994) mendefinisikan kepercayaan adalah perilaku terhadap reliabilitas dan integritas perusahaan untuk memenuhi harapan pelanggan pada masa yang akan datang. Lau dan Lee (1999) menyatakan kepercayaan sebagai kesediaan seseorang untuk menggantungkan dirinya untuk pihak lain dengan suatu resiko tertentu yang berdasarkan dengan keyakinan. Berdasarkan definisi diatas, dapat disimpulkan bahwa kepercayaan adalah kesediaan seseorang untuk menggantungkan dirinya pada pihak lain dengan memiliki harapan terhadap individu atau kelompok yang dapat diandalkan.

\section{Keputusan Pembelian}

Menurut Peter dan Olson dalam Sangadji dan Sopiah (2013) pengambilan keputusan konsumen merupakan proses pemecahan masalah yang diarahkan pada suatu sasaran. Inti dari pengambilan keputusan konsumen adalah proses pengintegrasian yang mengombinasikan dengan pengetahuan untuk mengevaluasi dua perilaku alternatif atau lebih, dan memilih salah satu diantaranya. Menurut Kotler dan Armstrong (2013), menyatakan keputusan pembelian adalah tahapan proses pengambilan keputusan ketika konsumen secara nyata melakukan pembelian sebuah produk atau jasa. Berdasarkan definisi diatas, dapat disimpulkan bahwa keputusan pembelian merupakan tahapan pemecahan masalah dalam proses pengambilan keputusan ketika konsumen melakukan suatu pembelian barang atau jasa.

\section{Kaitan antara e-WOM dan keputusan pembelian}

Berdasarkan penelitian yang dilakukan oleh Prasad et al. (2018) terhadap generasi Y di India, mendapatkan hasil bahwa e-WOM memiliki pengaruh yang positif terhadap keputusan pembelian. Penelitian yang dilakukan oleh Chen et al. (2015) yang meneliti dampak e-WOM terhadap keputusan pembelian pada saat musim liburan di Inggris, juga menunjukkan pengaruh yang positif.

\section{Kaitan antara persepsi nilai dan keputusan pembelian}

Chi et al. (2011) melakukan penelitian tentang pilihan konsumen di Taiwan, dalam penelitiannya terdapat hasil bahwa persepsi nilai memiliki pengaruh positif terhadap keputusan pembelian. Handi et al., (2018) meneliti tentang pengguna aplikasi Go-Food di Indonesia, mendapatkan hasil bahwa persepsi nilai memiliki pengaruh yang positif terhadap keputusan pembelian.

\section{Kaitan antara kepercayaan dan keputusan pembelian}

Chin et al. (2009) meneliti tentang kemauan konsumen untuk membeli secara online di Malaysia, mendapatkan hasil kepercayaan berpengaruh positif terhadap keputusan pembelian. Berdasarkan penelitian Anggraeni dan Madiawati (2016), mendapatkan hasil kepercayaan berpengaruh positif terhadap keputusan pembelian.

\section{Kaitan antara e-WOM dan kepercayaan}

Ladhari \& Michaud (2015) meneliti tentang pengaruh komen di media sosial Facebook terhadap pilihan hotel oleh konsumen, mendapatkan hasil positif antara e-WOM dengan kepercayaan. Penelitian yang dilakukan oleh Zainal et al. (2017) terhadap pelancong di Malaysia, mendapatkan hasil bahwan e-WOM memiliki pengaruh yang positif terhadap kepercayaan. 


\section{Kaitan antara persepsi nilai dan kepercayaan}

Berdasarkan penelitian yang dilakukan oleh Pooe (2013) di Afrika Selatan mendapatkan hasil bahwa persepsi nilai berpengaruh positif terhadap kepercayaan. Berdasarkan penelitian yang dilakukan oleh Lai (2015) mendapatkan hasil bahwa persepsi nilai berpengaruh positif terhadap kepercayaan.

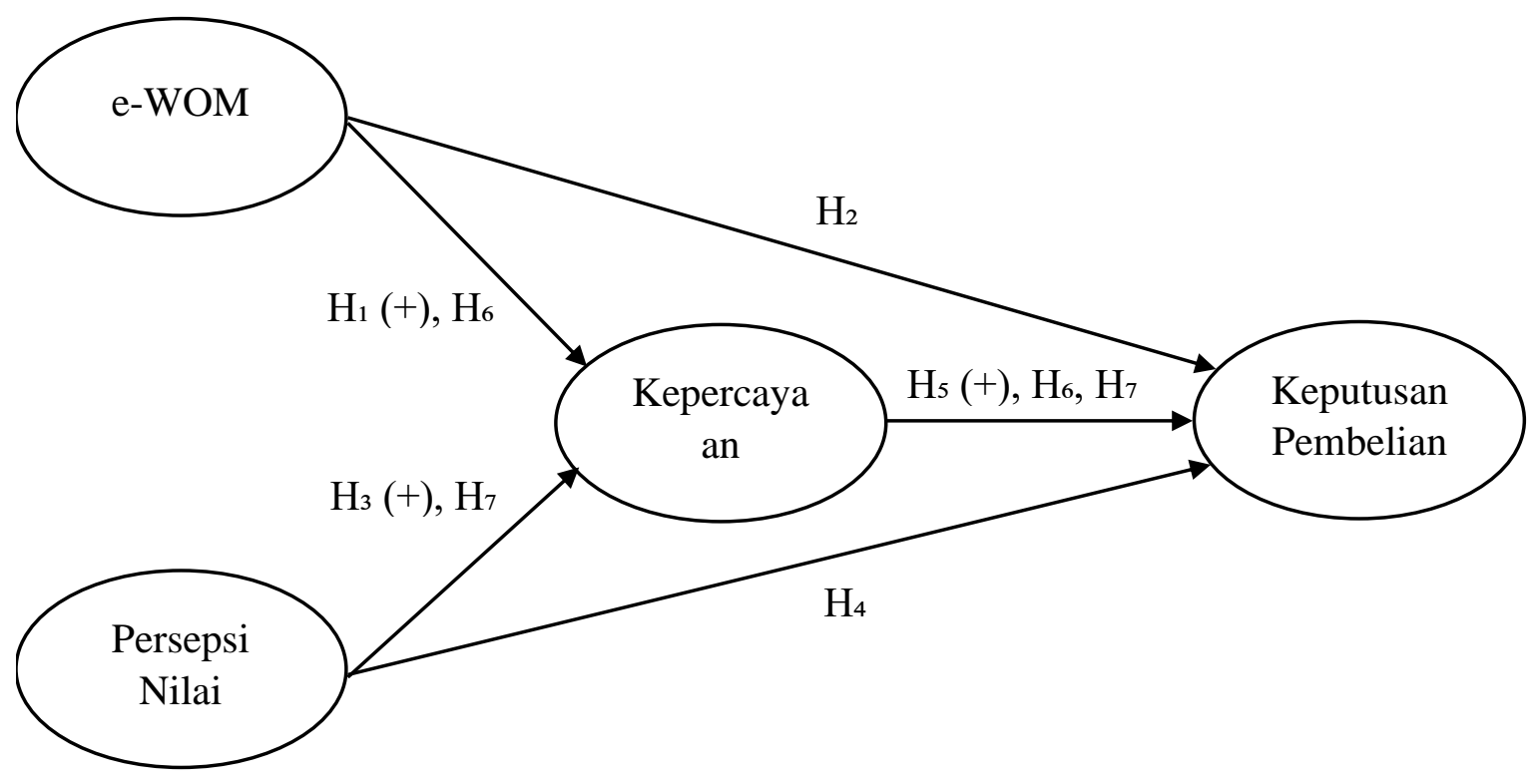

Gambar 1. Model penelitian

Hipotesis dalam penelitian ini adalah sebagai berikut:

$\mathrm{H}_{1}$ : e-WOM memiliki pengaruh yang positif terhadap kepercayaan.

$\mathrm{H}_{2}$ : e-WOM memiliki pengaruh yang positif terhadap keputusan pembelian.

$\mathrm{H}_{3}$ : Persepsi nilai memiliki pengaruh yang positif terhadap kepercayaan.

$\mathrm{H}_{4}$ : Persepsi nilai memiliki pengaruh yang positif terhadap keputusan pembelian.

$\mathrm{H}_{5}$ : Kepercayaan memiliki pengaruh yang positif terhadap keputusan pembelian.

$\mathrm{H}_{6}$ : e-WOM memiliki pengaruh yang positif terhadap keputusan pembelian melalui kepercayaan sebagai variabel mediasi.

$\mathrm{H}_{7}$ : Persepsi nilai memiliki pengaruh yang positif terhadap keputusan pembelian melalui kepercayaan sebagai variabel mediasi.

\section{METODE PENELITIAN}

Subyek penelitian ini adalah seluruh konsumen ShopeeFood dan objek penelitian ini adalah keputusan pembelian konsumen Shopeefood. Populasi dari penelitian ini adalah seluruh konsumen Shopeefood. Teknik pemilihan sampel adalah dengan non-probability sampling dengan metode convenience sampling. Sample dalam penelitian ini adalah 100 yang menggunakan aplikasi ShopeeFood di Jakarta.

Teknik analisis merupakan model alternatif dari covariance-predictive berdasarkan structural equation model (SEM). Pada penelitian yang dilakukan ini akan menggunakan metode analisis data dengan menggunakan software SMARTPLS versi 3.0 yang dirancang untuk mengestimasi persamaan structural. PLS atau Partial Least Square adalah analisis persamaan structural (SEM) berbasis varian yang dapat melakukan pengujian model pengukuran sekaligus pengujian model structural (Ghozali 2014). Pengolahan data penelitian terdiri dari dua analisis yaitu outer model dan inner model. 


\section{HASIL DAN PEMBAHASAN}

\section{Hasil Uji Statistik}

Pada penelitian ini, pengujian outer model terdiri dari uji validitas dan reliabilitas. Pengujian inner model yang terdiri dari pengujian koefisien determinasi $\left(\mathrm{R}^{2}\right)$, uji $\mathrm{f}^{2}$ dan pengujian dengan metode bootstrapping serta pengujian terhadap hipotesis yang telah dirumuskan pada penelitian ini. Peneliti tidak menggunakan uji asumsi analisis data. Dikarenakan, telah menggunakan partial least square (PLS) yang merupakan teknik statistik multivariat yang dapat digunakan untuk menangani banyak variabel respon dan variabel eksplanatori.

\section{Profil Responden}

Berdasarkan data karakteristik responden, mayoritas responden adalah laki - laki (55\%), rentan usia antara 21 - 30 tahun (45\%), yang didominasi oleh pelajar/mahasiswa (43\%) dengan pendapatan perbulan berkisar antara 2.000.000-5.000.000 (70\%).

\section{Uji Validitas}

Validitas konvergen adalah ukuran validitas yang mengukur sejauh mana skala yang berkorelasi positif dengan ukuran lain dari konstruk yang sama (Malhotra, 2010). Dalam validitas konvergen, indikator individu dianggap signifikan secara praktis memiliki nilai outer loading > 0,5 (Abdillah and Hartono 2015). Berikut adalah hasil analisis nilai loading factor dari setiap indikator:

Tabel 1. Hasil Uji Discriminant Validity (Cross Loadings)

\begin{tabular}{|l|r|r|r|r|}
\hline & Kepercayaan (Z) & Keputusan Pembelian (Y) & Persepsi Nilai (X2) & e-WOM (X1) \\
\hline KEP1 & $\mathbf{0 , 8 1 9}$ & 0,674 & 0,628 & 0,614 \\
\hline KEP2 & $\mathbf{0 , 7 7 4}$ & 0,612 & 0,648 & 0,610 \\
\hline KEP3 & $\mathbf{0 , 7 8 3}$ & 0,642 & 0,622 & 0,622 \\
\hline KEP4 & $\mathbf{0 , 8 1 3}$ & 0,644 & 0,607 & 0,626 \\
\hline KEP5 & $\mathbf{0 , 8 4 8}$ & 0,715 & 0,651 & 0,707 \\
\hline KP1 & 0,499 & $\mathbf{0 , 6 9 8}$ & 0,564 & 0,597 \\
\hline KP2 & 0,675 & $\mathbf{0 , 8 2 2}$ & 0,749 & 0,779 \\
\hline KP3 & 0,694 & $\mathbf{0 , 8 3 7}$ & 0,616 & 0,591 \\
\hline KP4 & 0,642 & $\mathbf{0 , 7 9 9}$ & 0,761 & 0,723 \\
\hline KP5 & 0,736 & $\mathbf{0 , 8 4 5}$ & 0,713 & 0,666 \\
\hline PN1 & 0,651 & 0,709 & $\mathbf{0 , 8 5 2}$ & 0,740 \\
\hline PN2 & 0,696 & 0,742 & $\mathbf{0 , 8 3 2}$ & 0,734 \\
\hline PN3 & 0,730 & 0,774 & $\mathbf{0 , 8 7 5}$ & 0,821 \\
\hline PN4 & 0,638 & 0,724 & $\mathbf{0 , 8 6 6}$ & 0,741 \\
\hline PN5 & 0,613 & 0,699 & $\mathbf{0 , 8 4 4}$ & 0,655 \\
\hline e-WOM1 & 0,595 & 0,706 & 0,723 & $\mathbf{0 , 8 1 3}$ \\
\hline e-WOM2 & 0,617 & 0,655 & 0,648 & $\mathbf{0 , 7 9 9}$ \\
\hline e-WOM3 & 0,703 & 0,668 & 0,672 & $\mathbf{0 , 7 8 3}$ \\
\hline e-WOM4 & 0,627 & 0,650 & 0,669 & $\mathbf{0 , 7 9 9}$ \\
\hline e-WOM5 & 0,602 & 0,685 & 0,749 & $\mathbf{0 , 8 0 0}$ \\
\hline
\end{tabular}

\section{Uji Reliabilitas}

Reliabilitas adalah sebuah indeks yang diguakan untuk memberi tahu suatu alat ukur dapat dipercaya atau dapat diandalkan. Bila suatu alat pengukur dipakai dua kali - untuk mengukur gejala yang sama dan hasil pengukuran yang diperoleh relative konsisten, maka alat pengukur tersebut reliable. Jika Cronbach's alpha lebih dari $>0,6$ atau $>0,7$, maka dikatakan reliable dan jika Cronbach's alpha kurang dari < 0,6 atau < 0,7 data tersebut dikatakan tidak reliabel. 
Pada tahap pengujian ini, analisis reliabilitas dilakukan dengan melihat nilai Cronbach alpha dan Composite Reliability. Hasilnya seperti disajikan pada tabel berikut ini:

Tabel 2. Hasil Uji Reliabilitas

\begin{tabular}{|l|c|}
\hline Variabel & Composite Reliability \\
\hline Kepercayaan (Z) & 0,904 \\
\hline Keputusan Pembelian (Y) & 0,900 \\
\hline Persepsi Nilai (X2) & 0,931 \\
\hline e-WOM (X1) & 0,898 \\
\hline
\end{tabular}

\section{Uji $R$-Square}

Nilai R Square digunakan untuk mengukur tingkat variasi perubahan variabel independent terhadap variabel dependen. Nilai $\mathrm{R}^{2}$ berada di rentang angka 0 sampai 1 . Jika semakin tinggi nilai $\mathrm{R}^{2}$, dan atau semakin mendekati angka 1, maka semakin baik model yang digunakan.

Tabel 3. Hasil Uji R-Square

\begin{tabular}{|l|c|c|}
\hline & R-Square & R Square-Adjusted \\
\hline Kepercayaan $(\mathrm{Z})$ & 0,660 & 0,653 \\
\hline Keputusan Pembelian (Y) & 0,803 & 0,797 \\
\hline
\end{tabular}

\section{Uji Effect Size}

Pengujian effect size $\left(\mathrm{f}^{2}\right)$ dilakukan dengan tujuan untuk mengukur apakah variabel prediktor tersebut memiliki efek di dalam model structural.

Tabel 4. Hasil Uji $\mathrm{f}^{2}$

\begin{tabular}{|l|r|r|l|l|}
\hline & Kepercayaan (Z) & Keputusan Pembelian (Y) & Persepsi Nilai (X2) & $\begin{array}{c}\text { e-WOM } \\
\text { (X1) }\end{array}$ \\
\hline Kepercayaan (Z) & & 0,153 & & \\
\hline Keputusan Pembelian (Y) & & & & \\
\hline Persepsi Nilai (X2) & 0,114 & 0,168 & & \\
\hline e-WOM (X1) & 0,146 & 0,082 & & \\
\hline
\end{tabular}

Berdasarkan hasil perhitungan nilai uji $\mathrm{f}^{2}$, maka dapat disimpulkan bahwa variabel Perceived Quality yang digunakan pada penelitian ini memiliki efek yang tergolong kategori hubungan kuat di dalam model struktural karena nilai yang dihasilkan lebih dari 0,35. Sedangkan Perceived Price dan Social Influence tergolong kategori hubungan kecil.

\section{Uji Signifikansi Bootstrapping}

Uji signifikansi pada penelitian ini digunakan untuk melihat hubungan antara variabel penelitian dengan melihat hasil dari metode bootstrapping bagian $\mathrm{P}$ values. Bootstrapping atau pengujian hipotesis dilakukan dengan menggunakan tingkatan keyakinan 95\%. Bootstraping dilakukan untuk mengetahui apakah terdapat variabel independen yang secara parsial untuk memprediksi adanya variabel dependen yang secara signifikan. Kriteria yang dipakai untuk melakukan pengujian adalah sebagai berikut: Jika nilai $p$-value memiliki nilai tidak melebihi $5 \%$, maka hipotesis tidak akan ditolak. Mempunyai arti, adanya prediktor yang signifikan variabel independen terhadap variabel dependen. Jika nilai $p$-value memiliki nilai lebih besar dari 5\%, maka hipotesis ini akan ditolak. Mempunyai arti, bahwa bukan prediktor yang signifikan variabel independen terhadap variabel dependen. 
Tabel 5. Hasil Uji Signifikansi Pengaruh Langsung

\begin{tabular}{|l|r|r|}
\hline Hubungan Variabel & t-statistics & p-values \\
\hline e-WOM (X1) -> Kepercayaan (Z) & 3,648 & 0,000 \\
\hline e-WOM (X1) -> Keputusan Pembelian (Y) & 2,234 & 0,026 \\
\hline Persepsi Nilai (X2) -> Kepercayaan (Z) & 3,341 & 0,001 \\
\hline Persepsi Nilai (X2) -> Keputusan Pembelian (Y) & 2,622 & 0,009 \\
\hline Kepercayaan (Z) -> Keputusan Pembelian (Y) & 3,611 & 0,000 \\
\hline
\end{tabular}

Tabel 6. Hasil Uji Signifikansi Pengaruh Tidak Langsung

\begin{tabular}{|l|c|c|c|c|c|}
\hline & $\begin{array}{c}\text { Original } \\
\text { Sample (O) }\end{array}$ & $\begin{array}{c}\text { Sample } \\
\text { Mean } \\
(\mathbf{M})\end{array}$ & $\begin{array}{c}\text { Standard } \\
\text { Deviation } \\
\text { (STDEV) }\end{array}$ & $\begin{array}{c}\text { t-statistics } \\
(\mid \mathbf{O} / \text { STDEV|) }\end{array}$ & p-values \\
\hline $\begin{array}{l}\text { e-WOM (X1) -> Kepercayaan (Z) -> } \\
\text { Keputusan Pembelian (Y) }\end{array}$ & 0,133 & 0,134 & 0,058 & 2,303 & 0,022 \\
\hline $\begin{array}{l}\text { Persepsi Nilai (X2) -> Kepercayaan } \\
\text { (Z) -> Keputusan Pembelian (Y) }\end{array}$ & 0,118 & 0,114 & 0,044 & 2,676 & 0,008 \\
\hline
\end{tabular}

\section{Diskusi}

Hipotesis dalam penelitian ini adalah:

H1: E-WOM memiliki pengaruh yang positif terhadap kepercayaan.

Berdasarkan hasil pada Tabel 5, dapat diketahui bahwa variabel E-WOM memiliki pengaruh yang positif terhadap kepercayaan. Hal ini dibuktikan dengan nilai $\mathrm{p}$ values yang dihasilkan adalah sebesar 0,000 lebih kecil dari cut off value yang ditetapkan yaitu sebesar 0,05. Sehingga dapat disimpulkan bahwa $\mathrm{H} 1$ diterima.

H2: E-WOM memiliki pengaruh yang positif terhadap Keputusan Pembelian.

Berdasarkan hasil pada Tabel 5, dapat diketahui bahwa variabel E-WOM memiliki pengaruh yang positif terhadap Keputusan Pembelian. Hal ini dibuktikan dengan nilai $\mathrm{p}$ values yang dihasilkan adalah sebesar 0,026 lebih kecil dari cut off value yang ditetapkan yaitu sebesar 0,05. Sehingga dapat disimpulkan bahwa $\mathrm{H} 2$ diterima.

H3: Persepsi nilai memiliki pengaruh yang positif terhadap kepercayaan.

Berdasarkan hasil pada Tabel 5, dapat diketahui bahwa variabel Persepsi nilai memiliki pengaruh yang positif terhadap kepercayaan. Hal ini dibuktikan dengan nilai $p$ values yang dihasilkan adalah sebesar 0,001 lebih kecil dari cut off value yang ditetapkan yaitu sebesar 0,05. Sehingga dapat disimpulkan bahwa H3 diterima.

H4: Persepsi nilai memiliki pengaruh yang positif terhadap keputusan pembelian.

Berdasarkan hasil pada Tabel 5, dapat diketahui bahwa variabel Persepsi nilai memiliki pengaruh yang positif terhadap keputusan pembelian. Hal ini dibuktikan dengan nilai $\mathrm{p}$ values yang dihasilkan adalah sebesar 0,009 lebih kecil dari cut off value yang ditetapkan yaitu sebesar 0,05. Sehingga dapat disimpulkan bahwa H4 diterima.

H5: Kepercayaan memiliki pengaruh yang positif terhadap keputusan pembelian.

Berdasarkan hasil pada Tabel 5, dapat diketahui bahwa variabel Kepercayaan memiliki pengaruh yang positif terhadap keputusan pembelian. Hal ini dibuktikan dengan nilai $p$ values yang dihasilkan adalah sebesar 0,000 lebih kecil dari cut off value yang ditetapkan yaitu sebesar 0,05. Sehingga dapat disimpulkan bahwa H5 diterima. 
H6: E-WOM memiliki pengaruh yang positif terhadap keputusan pembelian melalui kepercayaan sebagai variabel mediasi.

Berdasarkan hasil pada Tabel 6, dapat diketahui bahwa variabel E-WOM memiliki pengaruh yang positif terhadap keputusan pembelian melalui kepercayaan sebagai variabel mediasi. Hal ini dibuktikan dengan nilai $\mathrm{p}$ values yang dihasilkan adalah sebesar 0,022 lebih kecil dari cut off value yang ditetapkan yaitu sebesar 0,05. Sehingga dapat disimpulkan bahwa H6 diterima.

H7: Persepsi nilai memiliki pengaruh yang positif terhadap keputusan pembelian melalui kepercayaan sebagai variabel mediasi.

Berdasarkan hasil pada Tabel 6, dapat diketahui bahwa variabel Persepsi nilai memiliki pengaruh yang positif terhadap keputusan pembelian melalui kepercayaan sebagai variabel mediasi. Hal ini dibuktikan dengan nilai p values yang dihasilkan adalah sebesar 0,008 lebih kecil dari cut off value yang ditetapkan yaitu sebesar 0,05 . Sehingga dapat disimpulkan bahwa H7 diterima.

\section{KESIMPULAN DAN SARAN}

E-WOM memiliki pengaruh yang positif terhadap kepercayaan. E-WOM memiliki pengaruh yang positif terhadap keputusan pembelian makanan menggunakan aplikasi ShopeeFood. Persepsi nilai memiliki pengaruh yang positif terhadap kepercayaan. Persepsi nilai memiliki pengaruh yang positif terhadap keputusan pembelian makanan menggunakan aplikasi ShopeeFood. Kepercayaan memiliki pengaruh yang positif terhadap keputusan pembelian makanan menggunakan aplikasi Shopeefood.

E-WOM memiliki pengaruh yang positif terhadap keputusan pembelian makanan menggunakan aplikasi ShopeeFood melalui kepercayaan sebagai variabel mediasi dan menunjukkan efek mediasi parsial. Persepsi nilai memiliki pengaruh yang positif terhadap keputusan pembelian makanan menggunakan aplikasi ShopeeFood melalui kepercayaan sebagai variabel mediasi dan menunjukkan efek mediasi parsial.

Kepercayaan mampu memediasi pengaruh E-WOM dan persepsi nilai terhadap keputusan pembelian makan pada aplikasi ShopeeFood. Oleh karena itu, disarankan agar ulasan dari pelanggan terutama dari media sosial dikelola dengan baik sehingga membuat konsumen percaya diri dalam menggunakan aplikasi ShopeeFood. Selain itu, perusahaan perlu meningkatkan kinerja aplikasi ShopeeFood seperti meluaskan jangkauan maupun jaringan layanan, menambah dan bekerja sama dengan lebih banyak tenant, memperbanyak fitur kedepannya lagi agar lebih baik. Dengan demikian konsumen akan meningkatkan keputusan pembelian makanan pada aplikasi ShopeeFood.

Peneliti selanjutnya disarankan untuk memasukkan variabel lain yang diduga mempunyai dampak terhadap Keputusan Pembelian makan pada aplikasi ShopeeFood misalnya kepuasan pengguna, promosi media sosial perusahaan dan kualitas layanan elektronik.

\section{REFERENSI}

Anggraeni, P. and Madiawati, P.N. (2016). Pengaruh kepercayaan dan kualitas informasi terhadap keputusan pembelian secara online pada situs www.traveloka.com. e-Proceeding of Management, 3(2), pp.1880-1887.

Chen, C., Nguyen, B., Klaus, P. “., \& Wu, M. (2015). Exploring electronic word-of-Mouth (eWOM) in the consumer purchase decision-making process: The case of online holidays Evidence from United Kingdom (UK) consumers. Journal of Travel \& Tourism Marketing, 
32(8), 953-970. https://doi.org/10.1080/10548408.2014.956165

Chi, H., Yeh, H. R., \& Tsai, Y. C. (2011). The Influences of Perceived Value on Consumer Purchase Intention: The Moderating Effect of Advertising Endorser. Journal of International Management Studies, 6(1).

Chin, A.J., Wafa, S.A.W.S.K. and Ooi, A.Y. (2009). The effect of internet trust and social influence towards willingness to purchase online in Labuan, Malaysia. International Business Research, [e-journal] 2(2), pp.72-81. http://dx.doi.org/10.5539/ibr.v2n2p72.

Chinomona, R., Okoumba, L. and Pooe, D. (2013). The impact of product quality on perceived value, trust and students' intention to purchase electronic gadgets. Mediterranean Journal of Social Sciences, 4(4), pp.463-472. https://doi.org/10.5901/mjss.2013.v4n14p463

Ghozali, Imam. 2014. Structural Equation Modeling, Metode Alternatif dengan Partial Least Square (PLS). Edisi 4. Semarang : Badan Penerbit Universitas Diponegoro

Hennig-Thurau, T., Gwinner, K. P., Walsh, G., \& Gremler, D. D. (2004). Electronic word-ofmouth via consumer-opinion platforms: What motivates consumers to articulate themselves on the internet? Journal of Interactive Marketing, 18(1), 38-52. https://doi.org/10.1002/dir.10073

Jalilvand, M. R., Esfahani, S. S., \& Samiei, N. (2012). Electronic word-of-mouth: Challenges and opportunities. Procedia Computer Science, 3, 42-46. https://doi.org/10.1016/j.procs.2010.12.008

Kotler, Philip \& Gary Armstrong. (2013). Prinsip-prinsip Pemasaran, Edisi ke-12. Penerbit Erlangga.

Kotler, Philip and Kevin Lane Keller, (2016). Marketing Management, $15^{\text {th }}$ Edition New Jersey: Pearson Pretice Hall, Inc.

Ladhari, R., \& Michaud, M. (2015). EWOM effects on hotel booking intentions, attitudes, trust, and website perceptions. International Journal of Hospitality Management, 46, 36-45. https://doi.org/10.1016/j.ijhm.2015.01.010

Lai, Y.H., (2015). Enhance online purchase intentions: The role of rerceived value, trust, and commitment. Journal of Tourism and Hospitality Management, 3(2), pp.89-99.

Lau, G.T. dan S.H. Lee (1999), Consumers Trust In Brand and The Link to Brand Loyalty, Journal of Market Focused Management. (4) :341 - 370.

Machado, E. M., \& Rodhiah, R. (2020). Pengaruh Self-Expression dan Brand Trust Terhadap Electronic-Word Of Mouth dengan Brand Love sebagai Mediasi pada Konsumen Vans di Jakarta. Jurnal Muara Ilmu Ekonomi dan Bisnis, 5(1), 49-58.

Morgan, R. M., \& Hunt, S. D. (1994). The commitment-trust theory of relationship marketing. Journal of Marketing, 58(3), 20. https://doi.org/10.2307/1252308

Prasad, S., Garg, A., \& Prasad, S. (2018). Purchase decision of Generation Y in an online environment. Marketing Intelligence \& Planning, 37(4), 372-385. https://doi.org/10.1108/mip-02-2018-0070

Putra, T. W., \& Keni, K. (2020). Brand Experience, Perceived Value, Brand Trust Untuk Memprediksi Brand Loyalty: Brand Love Sebagai Variabel Mediasi. http://dx.doi.org/10.24912/jmieb.v4i1.7759

Sangadji, Etta Mamang dan Sopiah. (2013). Perilaku Konsumen. Yogyakarta: Andi,

Soares, A. M., Pinho, J. C., \& Nobre, H. (2012). From Social to Marketing Interactions: The Role of Social Networks. Journal of Transnational Management, 17(1), 45-62. https://doi.org/10.1080/15475778.2012.650085

Tjiptono, Fandy dan Gregorius chandra. (2016). Service, Quality \& Satisfaction Yogyakarta: Penerbit Andi

Zainal, N. T., Harun, A., \& Lily, J. (2017). Examining the mediating effect of attitude towards electronic words-of mouth (eWOM) on the relation between the trust in eWOM source and 
intention to follow eWOM among Malaysian travellers. Asia Pacific Management Review, 22(1), 35-44. https://doi.org/10.1016/j.apmrv.2016.10.004

Zamudio, C. (2016). Matching with the stars: How brand personality determines celebrity endorsement contract formation. International Journal of Research in Marketing, 33(2), 409-427. https://doi.org/10.1016/j.ijresmar.2015.07.002 